\title{
Sterile cerebrospinal fluid ascites presenting as high SAAG ascites: a case report
}

\author{
Darrick K. Li ${ }^{*} \mathbb{D}$, Jesse M. Platt, Jessica E. S. Shay and Joseph C. Yarze
}

\begin{abstract}
Background: Cerebrospinal fluid ascites is a rare complication of ventriculoperitoneal shunting and is the result of infection and subsequent peritonitis in the majority of cases. Sterile cerebrospinal fluid ascites in which no known infectious etiology is identified, is even more unusual.

Case Presentation: A 26-year-old female with Loeys-Dietz syndrome and congenital hydrocephalus treated with a ventriculoperitoneal shunt, was evaluated after developing new-onset ascites of unclear etiology after abdominal surgery for repair of an aortic aneurysm requiring multiple therapeutic paracenteses. Her serum ascites albumin gradient (SAAG) was greater than 1.1, suggestive of a portal hypertensive etiology. Gram stain as well as multiple cultures of her ascites fluid were both negative. Extensive investigation including hepatic venous portal gradient measurement and liver biopsy revealed no evidence of hepatic disease or portal hypertension. She was ultimately found to have sterile cerebrospinal fluid ascites which was treated successfully with a peritoneovenous shunt.

Conclusion: Sterile cerebrospinal fluid ascites is a rare clinical entity that has only been reported approximately 50 times in the medical literature. In this report, we also highlight it as a rare cause of high SAAG ascites. Moreover, we describe the use of a peritoneovenous shunt as a novel therapeutic option in the management of this condition.
\end{abstract}

Keywords: Ascites, Cerebrospinal fluid, Serum ascites albumin gradient, Peritoneovenous shunt, Case report

\section{Background}

Ascites is a common clinical problem for which hepatic cirrhosis represents $\sim 80 \%$ of all cases, while non-hepatic causes including peritoneal malignancy $(12 \%)$, cardiac failure (5\%), and peritoneal tuberculosis $(2 \%)$ constitute most of the remaining etiologies [1]. A thorough evaluation, including assessment of the serum ascites albumin gradient (SAAG), is crucial to identifying the cause of the ascites and implementing an appropriate course of treatment. Low SAAG $(<1.1 \mathrm{~g} / \mathrm{dL})$ ascites is most frequently caused by peritoneal malignancy or tuberculosis and can also be caused by nephrotic syndrome, pancreatic ascites, or protein-losing enteropathy. A SAAG of $\geq 1.1 \mathrm{~g} / \mathrm{dL}$ has been shown to be effective at identifying patients with ascites secondary to sinusoidal portal hypertension. Interestingly, the SAAG has been shown

\footnotetext{
* Correspondence: dkli@partners.org

Division of Gastroenterology, Department of Medicine, Massachusetts General Hospital, 55 Fruit Street, Blake Building, 4th Floor, GI Unit, Boston, MA 02114, USA
}

to correlate with hepatic sinusoidal pressure and the threshold of $1.1 \mathrm{~g} / \mathrm{dL}$ roughly corresponds to a portal pressure gradient of $12 \mathrm{mmHg}$ [2], the pressure that is thought to be necessary for the development of ascites in patients with cirrhosis. High SAAG ascites can also be the result of other disease processes including cardiac failure, alcoholic hepatitis, and Budd-Chiari syndrome. In this report, we describe a case of high SAAG ascites secondary to sterile cerebrospinal fluid accumulation.

\section{Case presentation}

A 26-year-old female with Loeys-Dietz syndrome complicated by multiple aortic aneurysms and aortic dissection, congenital hydrocephalus treated with a ventriculoperitoneal (VP) shunt, was evaluated after developing new-onset ascites of unclear etiology. She had recently undergone resection and grafting of a thoracoabdominal aortic aneurysm with multiple vascular bypasses complicated by bowel wall edema and injury to her inferior vena cava necessitating chest

(c) The Author(s). 2019 Open Access This article is distributed under the terms of the Creative Commons Attribution 4.0 International License (http://creativecommons.org/licenses/by/4.0/), which permits unrestricted use, distribution, and reproduction in any medium, provided you give appropriate credit to the original author(s) and the source, provide a link to the Creative Commons license, and indicate if changes were made. The Creative Commons Public Domain Dedication waiver (http://creativecommons.org/publicdomain/zero/1.0/) applies to the data made available in this article, unless otherwise stated. 
and abdominal washouts. On post-operative day ten, she developed abdominal distension. Physical examination revealed a thin, young woman with multiple abdominal incisions that were stapled, clean, dry and intact without evidence of erythema, purulent drainage or infection. Her abdomen was distended, with bulging flanks and evidence of shifting dullness. CT of her abdomen and pelvis revealed massive ascites and diffuse anasarca. Paracentesis was performed and three liters of straw-colored fluid was removed. Analysis of ascitic fluid revealed $225 \mathrm{WBCs} / \mathrm{mm}^{3}(60 \%$ neutrophils) with total protein $2.0 \mathrm{~g} / \mathrm{dL}$, albumin 1.1 $\mathrm{g} / \mathrm{dL}$, and SAAG of 1.5. Bacterial, viral, fungal, and mycobacterial cultures of the ascites were negative. Given the elevated SAAG, there was initial concern for underlying hepatic disease and portal hypertension. Liver biochemical tests, complete blood count, and urinalysis were normal. Doppler interrogation of the hepatic vasculature and echocardiography were normal. A shunt study of the ventriculoperitoneal shunt revealed a normally functioning shunt. Invasive hepatic venous pressure measurements were performed. This revealed a right atrial pressure of 6 $\mathrm{mmHg}$, free hepatic vein pressure of $8 \mathrm{mmHg}$ and a wedged hepatic vein pressure of $10 \mathrm{mmHg}$ for a hepatic venous portal gradient of $2 \mathrm{mmHg}$ (normal $<5$ $\mathrm{mmHg}$ ), demonstrating an absence of portal hypertension. Liver biopsy revealed hepatic parenchyma with mild sinusoidal dilation but without inflammation, steatosis, or fibrosis. A reticulin stain revealed mild irregularity of hepatic cords and focal nodularity but this was not felt to be diagnostic of nodular regenerative hyperplasia (Fig. 1). Given the results of the evaluation, a diagnosis of cerebrospinal fluid (CSF) ascites was made, possibly related to decreased peritoneal absorption in the setting of post-operative peritoneal inflammation. A peritoneovenous (Denver) shunt was successfully placed into the right internal jugular vein. Initially, her ascites remained persistent and there was concern regarding limited drainage through the Denver shunt. Conversion of her existing VP shunt to a ventriculoatrial (VA) shunt was considered but given her underlying genetic vasculopathy and potential cardiac risks of another procedure, this was deferred. The Denver shunt was evaluated and was deemed to be functioning properly. Over the next several weeks, her ascites gradually resolved and she required no further therapeutic paracenteses.

\section{Discussion and conclusions}

The SAAG is widely used to help elucidate the etiology of ascites. Ascites due to portal hypertension is characterized by a SAAG of $\geq 1.1 \mathrm{~g} / \mathrm{dL}$, and the ascitic fluid total protein is subsequently used to further differentiate the various causes of ascites in patients with a high SAAG [3]. Cirrhosis represents the most common cause of high SAAG ascites, but constrictive pericarditis, congestive heart failure, Budd-Chiari syndrome, and alcoholic hepatitis are also diagnostic considerations. Sterile CSF ascites is a rare complication of ventriculoperitoneal shunting and to date, there have been approximately 50 cases reported in the English literature. Of these, only four, including our own, report either a paired serum albumin and ascites albumin or a SAAG [4-6] (Table 1). In each of these cases, the SAAG is also reported to be $\geq 1.1$ $\mathrm{g} / \mathrm{dL}$. Our case corroborates that CSF ascites is within the differential diagnosis of high SAAG ascites. The pathophysiology of the high SAAG in patients with sterile CSF ascites remains speculative but likely reflects the inherently low albumin content in sterile CSF fluid as a result of the blood-CSF barrier and the absence of de novo albumin synthesis in the central nervous system [7].

Loeys-Dietz syndrome (LDS) is an autosomal dominant connective tissue disorder first described in 2005, characterized by aortic aneurysms, generalized arterial tortuosity, hypertelorism, and cleft palate. LDS has been described due to mutations in the transforming growth factor $\beta$ I (TGFBR1), transforming growth factor $\beta$ II (TGFBR2), transforming growth factor $\beta 2$ ligand gene (TGFB2), and the decapentaplegic homolog 3 (SMAD3) [8]. Clinical complications of LDS are primarily a result of vascular complications including aortic dissection and aneurysmal rupture, which often require aortic surgery as was the case in our patients. Gastrointestinal complications including constipation as well as higher prevalence of eosinophilic gastrointestinal disease have been reported, but hepatic complications specifically related to LDS have not been reported.

Our case is also notable for the successful use of a Denver shunt in the management of CSF ascites, which has not been previously reported. Denver shunts have been successfully used in the management of portal hypertensive and malignant ascites and rely on the principle that ascites flows down a pressure gradient from the peritoneal cavity into the central venous circulation $[9,10]$. Backflow of blood is prevented through the use of a one-way valve chamber that lies in the subcutaneous tissue that can be compressed to promote flow and avoid blockage. Complications include infection, blockage, venous thrombosis, and disseminated intravascular coagulation. In the literature, CSF ascites has been treated primarily with conversion of the existing VP shunt to a VA shunt [4]. Our case demonstrates that the use of a Denver shunt may be a safe and viable 
A.

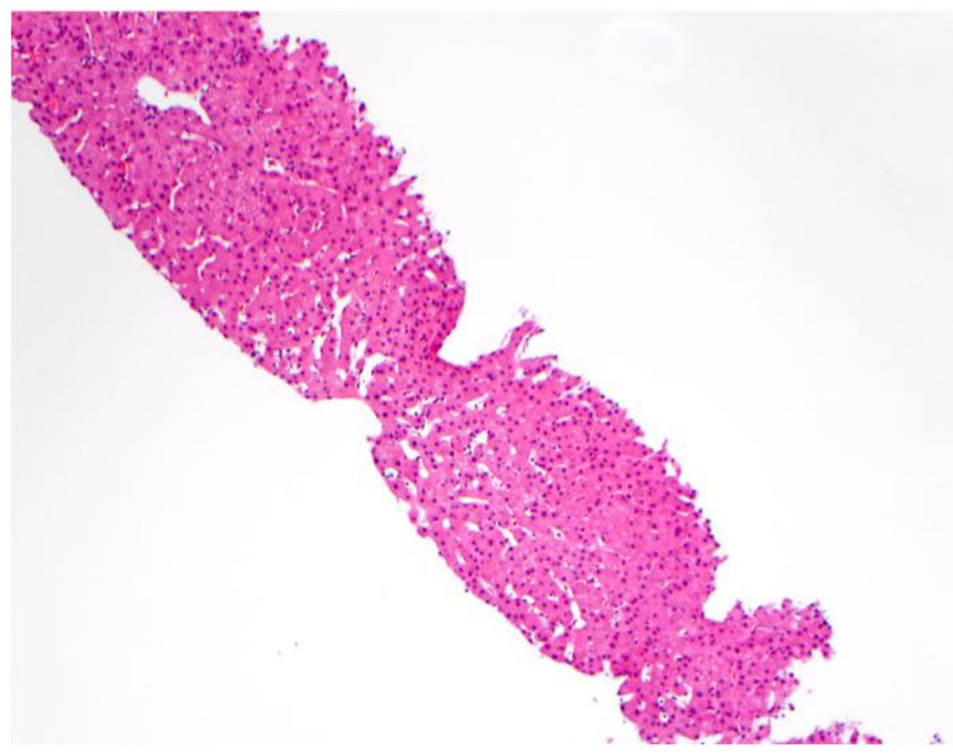

B.

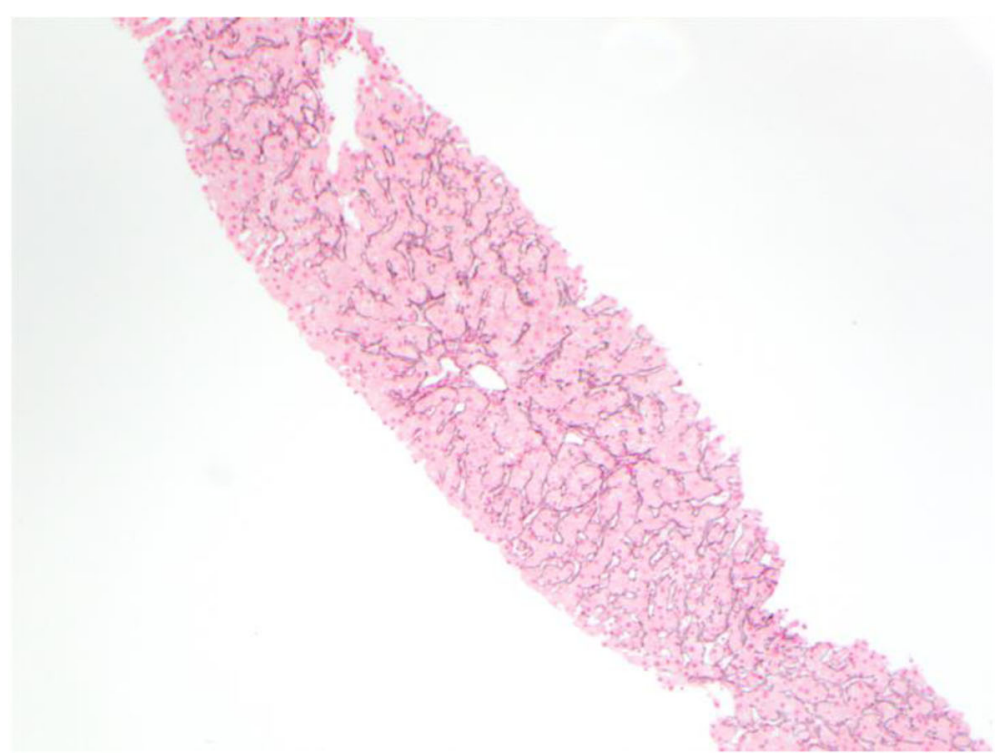

Fig. 1 Liver biopsy specimen showing largely normal hepatic parenchyma with mild sinusoidal dilatation with (a) hemotoxylin and eosin staining (10x magnification) or (b) reticulin staining (10x magnification)

Table 1 Published cases of CSF ascites with reported SAAG values

\begin{tabular}{lllll}
\hline Case & Age & Predisposing pathology for CSF ascites formation & SAAG (g/dL) & Treatment \\
\hline This case & 26years & Abdominal surgery & 1.5 & Denver shunt, paracenteses \\
Longstreth and Buckwalter [4] & 28years & Inflammatory reaction to silicone tubing & 2.5 & Ventriculoatrial shunt \\
Das et al. [5] & 7years & Chemotherapy & High (not specified) & Ventriculoatrial shunt \\
Comba et al. [6] & 6years & Unknown & 2.75 & Ventriculoatrial shunt \\
\hline
\end{tabular}


alternative treatment modality to VA shunting for this condition.

In this report, we characterize sterile cerebrospinal fluid ascites as a rare cause of high SAAG ascites, highlighting the need for clinician awareness for this rare entity in the differential diagnosis of ascites. Moreover, we describe the use of a peritoneovenous shunt for the first time as a novel and viable therapeutic option in the management of this condition.

\section{Abbreviations}

CSF: Cerebrospinal fluid; SAAG: Serum ascites albumin gradient;

VA: Ventriculoatrial; VP: Ventriculoperitoneal

\section{Acknowledgements}

Not applicable.

\section{Authors' contributions}

DKL - wrote manuscript, acquisition and analysis of data; JMP - acquisition and analysis of data; JES - acquisition and analysis of data; JCY - acquisition and analysis of data; all authors have read and approved the manuscript for submission.

\section{Funding}

None.

\section{Availability of data and materials}

Data sharing is not applicable to this article as no datasets were generated or analyzed during the current study.

\section{Ethics approval and consent to participate} Not applicable.

\section{Consent for publication}

Written informed consent has been obtained from the patient for their personal and clinical details to be included in the publication of this case report.

\section{Competing interests}

The authors declare that they have no competing interests.

Received: 4 October 2019 Accepted: 13 November 2019

Published online: 27 November 2019

References

1. McHutchison J. Differential diagnosis of ascites. Semin Liver Dis. 1997;17(03): 191-202.

2. Hoefs JC. Serum protein concentration and portal pressure determine the ascitic fluid protein concentration in patients with chronic liver disease. J Lab Clin Med. 1983;102(2):260-73.

3. Runyon BA, Montano AA, Akriviadis EA, Antillon MR, Irving MA, McHutchison JG. The serum-ascites albumin gradient is superior to the exudate-transudate concept in the differential diagnosis of ascites. Ann Intern Med. 1992;117(3):215.

4. Longstreth GF, Buckwalter NR. Sterile cerebrospinal fluid ascites and chronic peritonitis. N Engl J Med. 2001;345(4):297-8.

5. Das S, Bhansali A, Upreti V, Dutta P, Gupta SK, Ananthraman R, et al. A child with suprasellar mass and ascites. BMJ Case Rep. 2010;12:2010.

6. Comba A, Gülenç N, Caltepe G, Dağçınar A, Yüce Ö, Kalaycı AG, et al. Ascites and abdominal pseudocyst: two uncommon ventriculoperitoneal shunt complications in two cases. Turk J Pediatr. 2013;55(6):655-8.

7. Tumani H, Huss A, Bachhuber F. The cerebrospinal fluid and barriers anatomic and physiologic considerations. Handb Clin Neurol. 2018;146: $21-32$.

8. MacCarrick G, Black JH, Bowdin S, El-Hamamsy I, Frischmeyer-Guerrerio PA, Guerrerio AL, et al. Loeys-Dietz syndrome: a primer for diagnosis and management. Genet Med. 2014;16(8):576-87.
9. White MA, Agle SC, Padia RK, Zervos EE. Denver peritoneovenous shunts for the management of malignant ascites: a review of the literature in the post LeVeen era. Am Surg. 2011;77(8):1070-5.

10. Martin LG. Percutaneous placement and Management of the Denver Shunt for portal hypertensive ascites. Am J Roentgenol. 2012;199(4):W449-53.

\section{Publisher's Note}

Springer Nature remains neutral with regard to jurisdictional claims in published maps and institutional affiliations.
Ready to submit your research? Choose BMC and benefit from:

- fast, convenient online submission

- thorough peer review by experienced researchers in your field

- rapid publication on acceptance

- support for research data, including large and complex data types

- gold Open Access which fosters wider collaboration and increased citations

- maximum visibility for your research: over $100 \mathrm{M}$ website views per year

At BMC, research is always in progress.

Learn more biomedcentral.com/submission 